\title{
One-Step Biocatalytic Synthesis of Sustainable Surfactants Using Selective Amide Bond Formation
}

\author{
Max Lubberink, Christian Schnepel, Christopher R. Baldwin, Nicholas J. Turner and Sabine L. \\ Flitsch*[a]
}

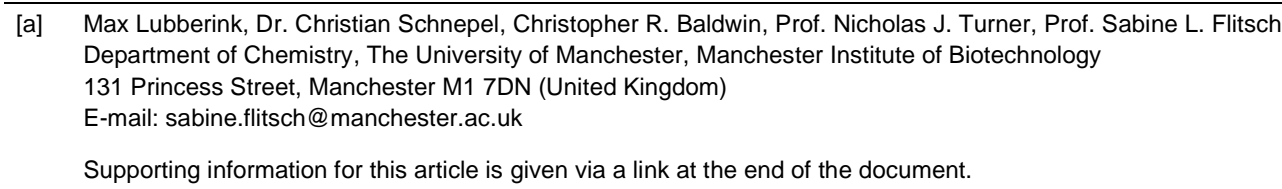

\begin{abstract}
N$-alkanoyl- $N$-methylglucamides (MEGAs) are non-toxic surfactants widely used in pharmaceutical and biochemical applications and hence more sustainable syntheses towards these compounds are highly desired. Here we present an aqueous, enzymatic synthesis route towards MEGAs and analogues using carboxylic acid reductase (CAR), which has been engineered to catalyse amide bond formation (CAR-A). Compared to lipase catalysed reactions, this biocatalyst is capable of selective amide bond formation between amino-polyols and fatty acids without the competing esterification reaction being observed. The wide substrate scope of CAR-A catalysed amidation was exemplified by the synthesis of 16 amides including several commercially relevant targets. The ATP co-factor could be recycled from cheap polyphosphate using a kinase. This work establishes acyl-phosphate mediated chemistry as a selective strategy for biocatalytic amide bond formation in the presence of competing alcohol functionalities.
\end{abstract}

Surfactants are a ubiquitous class of compounds offering a wide range of applications in pharmaceuticals, cosmetics, detergents, emulsifiers, and foaming agents. ${ }^{[1,2]}$ Since they contribute to a significant proportion of the total amount of chemicals produced worldwide (currently 16.5 megatons per year), there is significant interest in developing surfactants from renewable resources and sustainable synthesis methods. ${ }^{[3,4]}$

Non-ionic surfactants [e.g. $\mathrm{N}$-alkanoyl- $\mathrm{N}$-methylglucamides (MEGAs)], have the advantage over ionic surfactants in that they are non-toxic, stable, and possess greater cross-compatibility. They are therefore widely utilized in pharmaceutical and biochemical applications. ${ }^{[4]}$ In particular, due to the biodegradability of MEGAs and the fact that they are derived from renewable starting materials, these surfactants are regarded as green chemicals with a low environmental impact. ${ }^{[5]}$

The most common industrial method towards MEGAs utilizes reductive amination of glucose with methylamine to afford $N$ methyl-D-glucamine (1). $\mathbf{1}$ is an inexpensive and non-toxic compound that has been an approved drug excipient for decades. ${ }^{[6]}$ This substrate is then coupled to a fatty acid via chemical amide bond formation, typically using sodium methoxide which requires careful handling under completely dry conditions. ${ }^{[4]}$ In attempts to develop a less toxic and greener approach to the synthesis of MEGAs, enzymatic methods have gained some interest over the years. Maugard et al. have reported a lipase catalysed synthesis towards glucamide surfactants using either hexane or 2-methyl-2-butanol as a solvent. ${ }^{[7]}$ This method was

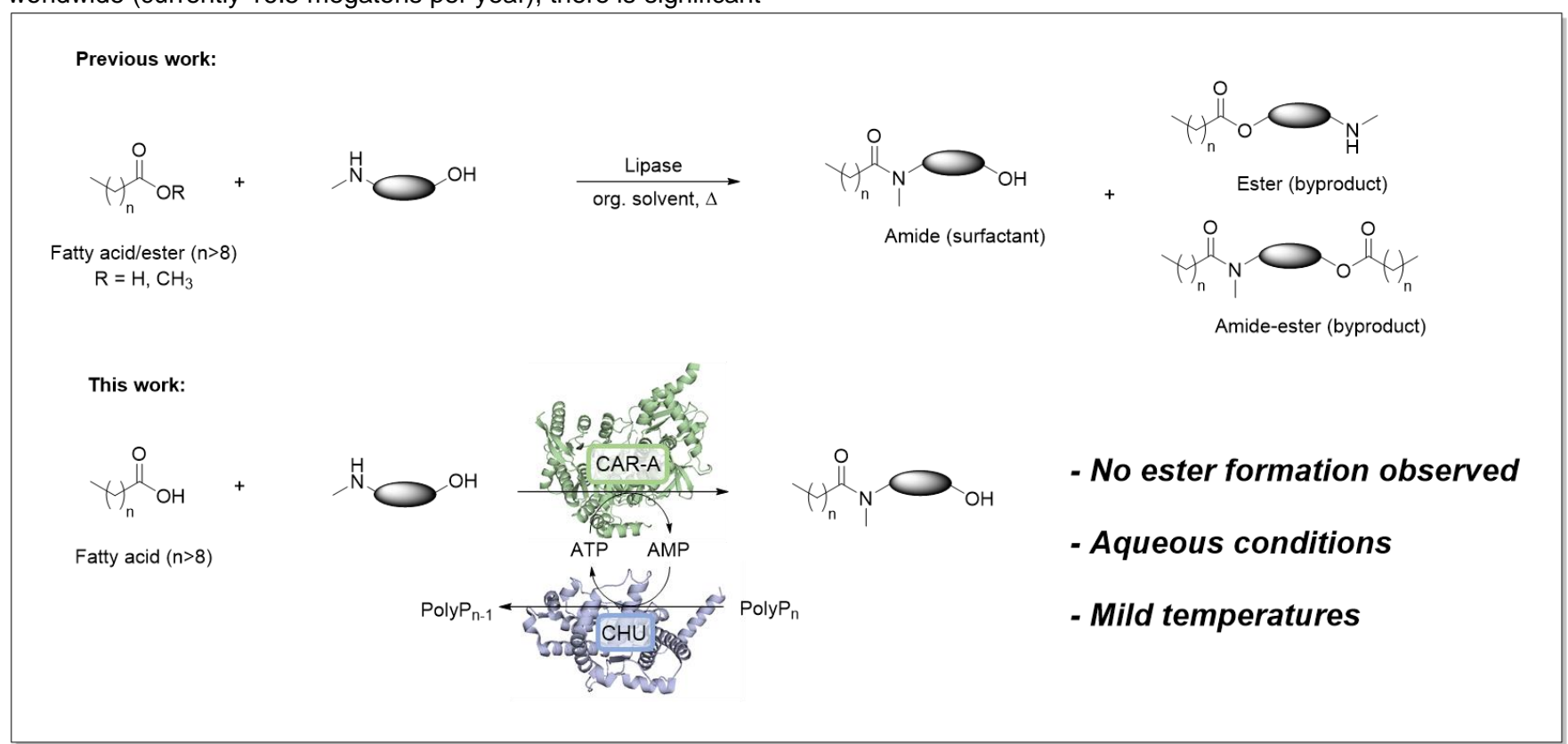

Figure 1. Comparison of lipase catalysed synthesis of MEGA surfactants in organic solvents (previous work) with highly selective CAR-A catalysed synthesis of surfactants using ATP - the cofactor can be recycled in situ using the kinase CHU (this work). 
optimized by Gaber et al. using a solvent-free system at $90^{\circ} \mathrm{C} .{ }^{[4]}$ These lipase-catalyzed reactions using 1 and either a fatty acid or a fatty acid methyl ester yield a mixture of amide (target product) and ester and amide-ester by-products (see Figure 1). ${ }^{[5]}$

The industrial need for alternative, more sustainable processes towards the synthesis of MEGAs is exemplified by the recent "Sugar Surfactant Open Innovation Challenge" announced by the Swiss multinational company Clariant. ${ }^{[8]}$ As amide bonds are prevalent motifs in many natural products and pharmaceuticals, there has been growing interest in the development of aqueous amidation methods under benign conditions. ${ }^{[9]}$ In recent years, the field of biocatalysis has provided a growing amount of options for this reaction, in particular with ATP-dependent enzymes forming an acyl-adenylate intermediate having gained increasing interest. ${ }^{[10-14]}$

Carboxylic acid reductases (CARs) are ATP and NADPH dependent enzymes capable of selectively reducing carboxylic acids to aldehydes and are emerging biocatalytic platforms in both academia and industry. ${ }^{[15]}$ CARs are multidomain proteins and the reduction of carboxylic acids proceeds through activation of the acid by ATP in the adenylation domain, followed by a transfer of the acyl group onto an enzyme-bound phosphopantetheine arm. This thioester intermediate is subsequently delivered to the reductase domain where it gets reduced using NADPH. ${ }^{[16]}$ It has previously been shown that CARs are capable of amide bond formation when the NADPH is substituted for an excess of amine nucleophile. ${ }^{[17]}$ Subsequently, it was found that using a truncated construct of CAR consisting of a stand-alone adenylation domain (CAR-A) was more effective in amide bond formation, and optimization of this process allowed for the selective monoacylation of symmetrical diamines. ${ }^{[18]}$

A recent study showed that CARs are also capable of ester formation, yet requiring significant amounts of imidazole catalyst. 1000 -fold excess concentrations. ${ }^{[19]}$ Encouraged by these results, we were interested in the selective amide bond formation between acids and multifunctional compounds like amino polyols catalyzed by CAR-A, without any unwanted ester or amide-ester byproducts. CARs are particularly attractive for this approach because of their wide substrate scope, which includes fatty Moreover, the alcohol nucleophile had to be provided in over

acids. ${ }^{[20,21]}$ For example, the recently published acyltransferase (MsAcT) mutants appear limited to short-chain aliphatic acyl donors. ${ }^{[22,23]}$

With regard to the amino sugar nucleophiles, these are considered challenging substrates in many biocatalytic methods, because of their high polarity, asymmetry, and cross-reactivity. ${ }^{[24]}$ For example, coronafacic acid ligases (CfaLs) are limited to aamino acids as nucleophiles and the amide synthase McbA is not suitable for accepting secondary amines. ${ }^{[25-27]}$ We were therefore interested in the question of whether CAR-based amide synthases could fill the need for the selective biocatalytic formation of $\mathrm{N}$-alkanoyl amide based surfactants as outlined in Figure 1

To test this hypothesis, $\mathrm{N}$-methylglucamine 1 was reacted with a number of carboxylic acids using our previously described truncated CAR-A construct derived from CARmm from Mycobacterium marinum. ${ }^{[28]}$ Starting with 3-fluoro cinnamic acid, a previously described substrate of the enzyme, we observed full conversion to a single reaction product on both LC-MS and ${ }^{19} \mathrm{~F}$ NMR (Supporting Information (SI)). The use of ${ }^{19} \mathrm{~F}-\mathrm{NMR}$ as a detection method allowed us to investigate crude reaction mixtures for competing ester bond formation, which was not observed. Next, reaction of 1 with decanoic acid led to the target surfactant MEGA-10 (4, figure $2 \mathrm{~A}$ ) with over $99 \%$ conversion, as determined by RP-HPLC at a wavelength of $210 \mathrm{~nm}$, using a commercial standard as a reference $(\mathrm{SI})$. Using these reaction conditions, a range of fatty acids of different chain lengths were successfully coupled to $\mathbf{1}$ yielding the commercial targets MEGA8 2, MEGA-9 3, MEGA-10 4, and the less commonly available MEGA-12 5 (Figure 2A). At low substrate concentrations (1mM) excellent yields were observed which again supported the observation that amide bond formation was highly selective over ester bond formation. At higher acid substrate loadings, the total product concentrations remained at similar levels, but yields decreased suggesting that enzyme loading was the rate-limiting step. Conversions: 2: $1 \mathrm{mM}$ : >99\%, $5 \mathrm{mM}: 75 \%, 10 \mathrm{mM}$ : 53\%, 3: $1 \mathrm{mM}:>99 \%, 5 \mathrm{mM}: 85 \%, 10 \mathrm{mM}: 62 \%, 4: 1 \mathrm{mM}:>99 \%, 5 \mathrm{mM}$ $86 \%, 10 \mathrm{mM}: 22 \%, 5: 1 \mathrm{mM}: 83 \%, 5 \mathrm{mM}: 25 \%, 10 \mathrm{mM}: 15 \%$.

To provide some additional experimental evidence for the observed selectivity of amide bond formation in these surfactants,

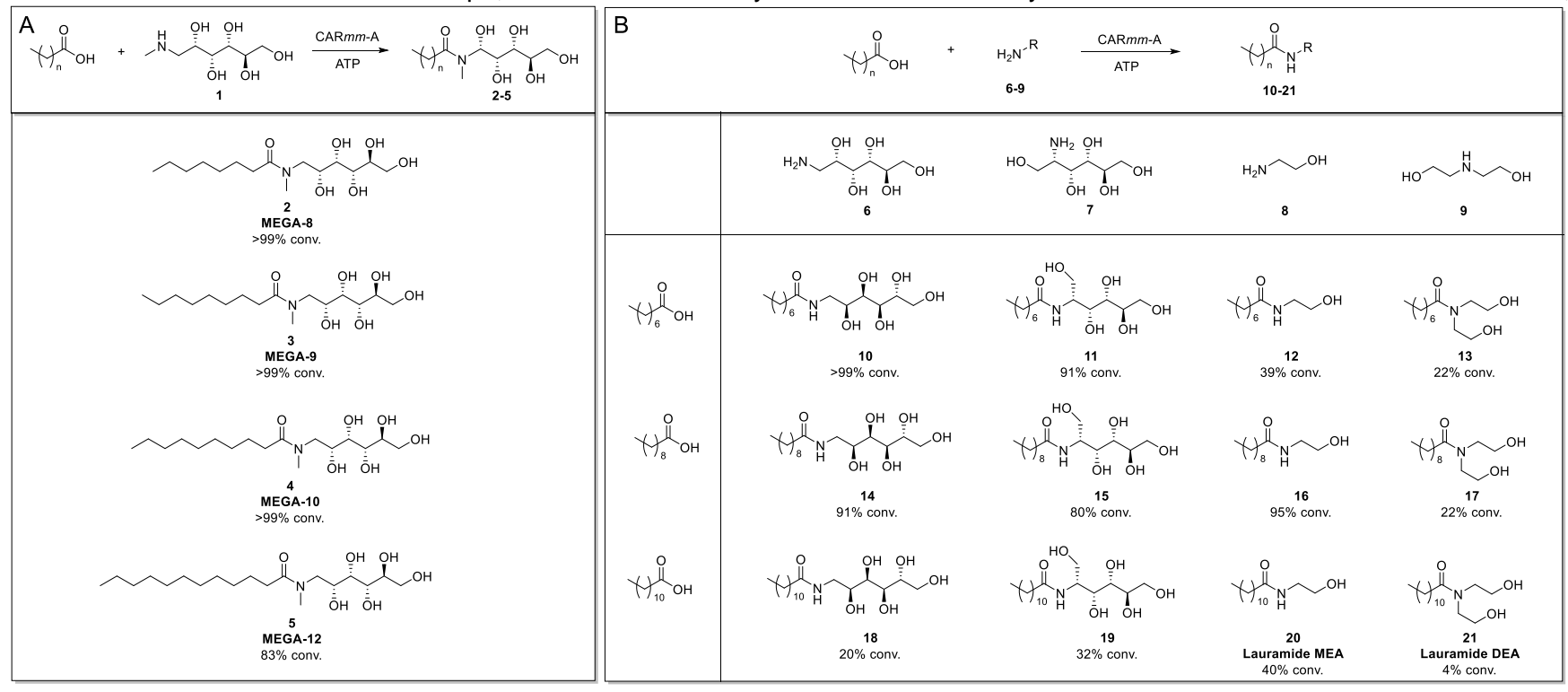

Figure 2 Synthesis of MEGA surfactants (A) and surfactant-like molecules (B) using CAR-A. Reaction conditions: Carboxylic acid (A: 1-10 mM, and B: 5 mM), amine 1 (175 mM), ATP $(50 \mathrm{mM}), \mathrm{MgCl}_{2}(50 \mathrm{mM})$, CAR-A $(1 \mathrm{mg} / \mathrm{mL}), \mathrm{HEPBS}$ buffer $(100 \mathrm{mM}), 5 \% \mathrm{DMSO}, 0.5 \mathrm{~mL} \mathrm{scale,} \mathrm{pH} 8.5,37{ }^{\circ} \mathrm{C}, 250 \mathrm{rpm}, 16 \mathrm{~h}$. 
we performed a biotransformation using ${ }^{13} \mathrm{C}$-labelled decanoic acid and $\mathbf{1}$ to monitor the reaction by ${ }^{13} \mathrm{C}-\mathrm{NMR}$. In particular, the carbonyl region of the spectrum should allow comparison between ester and amide product using a commercially available standard for MEGA-10 (4) as a reference (SI). This experiment showed very clearly that the only observed reaction product of the CAR-A catalyzed reaction between decanoic acid and $\mathbf{1}$ is the desired amide 4, without another carbonyl-containing (ester) side product being observed using this detection method.

These results led us to examine the scope of other amino alcohols for CAR-A catalyzed amide formation using octanoic, decanoic and dodecanoic acid as acyl donors. Using $5 \mathrm{mM}$ acid loadings, it was found that D-glucamine (6) was well accepted as amine donor forming secondary amides 10, 14 and 18 (Figure 2B). Next, we were interested to see if the amine moiety has to be located at the terminal position of the linear sugar for the amidation to occur. We synthesized glucosaminitol (7) via the reduction of glucosamine $(\mathrm{SI}) .{ }^{[29]}$ When reacted with the fatty acids, forming amides 11,15 and 19, this amino sugar containing a non-terminal amine on the 2-carbon showed good conversions, similar to the conversions for $\mathbf{6}$. This reiterates the wide scope of amine donors applied in this enzymatic method without any unwanted $O$ acylation reactions. Making further use of the selective amide bond formation between fatty acids and amino alcohols, we decided to look at ethanolamine (8) and diethanolamine (9) as amine donors, as their amide products would yield commercially available anti-foaming agents such as lauramide MEA and DEA (20 and 21), respectively. It was found that 8 (leading to primary amides 12, 16 and 20) showed higher conversions as an amine donor than 9 (leading to secondary amides 13, 17 and 21). In general, it was found that the increase in carbon chain length led to a decrease in conversion towards the amide, likely due to solubility reasons.

In order to perform these reactions on a preparative scale, the regeneration of ATP from polyphosphate using a class III polyphosphate kinase from Cytophaga hutchinsonii (CHU) was implemented. ${ }^{[18,30]}$ Biotransformations were successful on a 30 $\mathrm{mL}$ scale, using $10 \mathrm{mM}$ carboxylic acid, yielding the commercial surfactant MEGA-9 $(3,27 \%$ yield) and compound 10 (43\% yield). A benefit of this recycling system is that the less expensive AMP can be used, rather than ATP, with sodium polyphosphate as the phosphate source.

Our results suggest that the CAR-A-based amide synthesis is more selective than lipase-based methods, despite the fact that this reaction is a promiscuous activity for both enzyme classes. However, the reaction paths for each enzyme are very different as shown in Figure 3. The acylation reaction catalyzed by lipases is expected to proceed via an acyl-enzyme intermediate using the classic triad mechanism (figure 3a). ${ }^{[31]}$ The selectivity of the nucleophile ( $\mathrm{N}$ vs $\mathrm{O}$ ) would be expected to be controlled by the enzyme, with lipases naturally evolved to prefer ester substrates. A change in reactivity would involve protein engineering, with some interesting examples on catalytic triad enzymes reported recently. ${ }^{[23]}$

In contrast, CAR-A would be expected to generate a fatty acidacyl-AMP intermediate (figure $3 b$ ). The work by Chaiyen et al. shows that this intermediate does not react readily with alcohols: significant amounts of imidazole have to be added to the reaction mixture to be able to observe ester formation, i.e. requiring imidazole as a catalyst. ${ }^{[19]}$ Thus, we suggest that the selectivity is controlled by the intrinsic preference of acyl phosphates in water
A

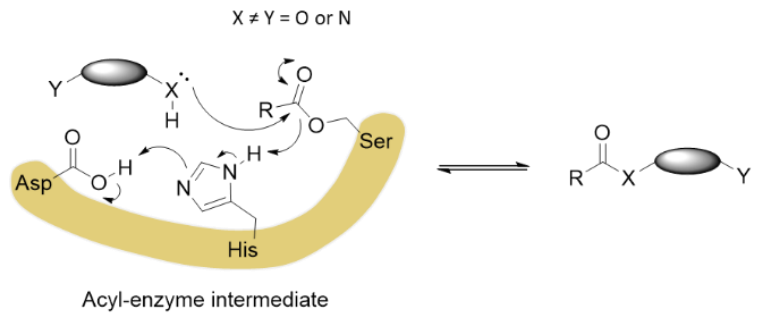

B

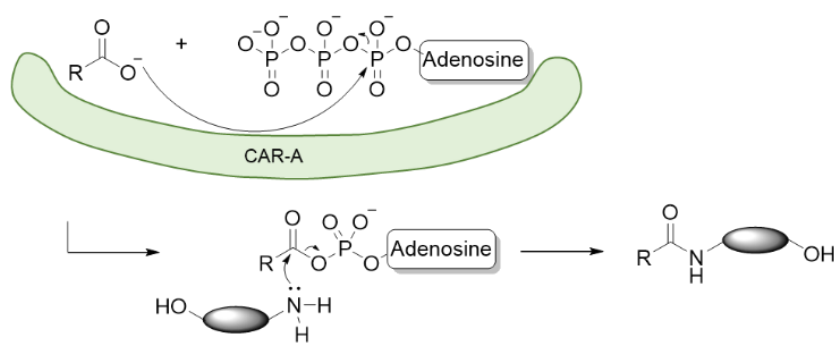

Figure 3 Comparison of the mechanisms of lipase and CAR-A catalyzed reactions between fatty acids/esters and amino alcohols. (a) lipase active site residues (in yellow) promoting the reaction via formation of an acyl-enzyme intermediate (b) proposed mechanism for CAR-A catalysed amidation: activesite adenylation step to form an acyl adenylate intermediate that preferentially reacts with amines over alcohols.

for amide over ester formation, which is documented in the literature. ${ }^{[32,33]}$

In summary, this study demonstrates the versatility of CAR-A for one-step, selective amide bond formation under aqueous conditions by starting from otherwise challenging, multifunctional substrates. It provides a highly selective alternative to current synthesis methods of MEGAs and related surfactants directly from acid and amines without ester-forming side reactions observed in lipase-catalyzed reactions. This amidation method might provide a valuable starting point for further reaction engineering and application in more industrially relevant processes.

\section{Acknowledgements}

CS, NJT and SLF acknowledge the EPSRC, BBSRC, and AstraZeneca plc for funding under the Prosperity Partnership EP/S005226/1. NJT acknowledges funding by the European Research Council under grant agreement no. 742987-BIO-HBORROW-ERC-2016-ADG. SLF acknowledges funding by the European Research Council under grant agreement no. 788231ProgrES-ERC-2017- ADG. ML thanks CoEBio3 for funding for a studentship.

Keywords: Biocatalysis • Sustainable Chemistry • Surfactants • Amides • Amino Alcohols

[1] A. Bhadani, A. Kafle, T. Ogura, M. Akamatsu, K. Sakai, H. Sakai, M. Abe, Curr. Opin. Colloid Interface Sci. 2020, 45, 124-135

[2] R. S. Heath, R. E. Ruscoe, N. J. Turner, Nat. Prod. Rep. 2021, DOI 10.1039/D1NP00027F.

[3] B. Vafakish, L. D. Wilson, Polysaccharides 2021, 2, 168-186.

[4] Y. Gaber, U. Törnvall, C. Orellana-Coca, M. Ali Amin, R. Hatti-Kaul, Green Chem. 2010, 12, 1817-1825.

[5] Y. Gaber, C. O. Åkerman, R. Hatti-Kaul, Chem. Cent. J. 2014, 8, 1- 
8.

K. Manley, A. Bravo-Nuevo, A. R. Minton, S. Sedano, A. Marcy, M.

Reichman, A. Tobia, C. M. Artlett, S. K. Gilmour, L. D. Laury-

Kleintop, G. C. Prendergast, J. Cell. Biochem. 2019, 120, 1205112062.

[7] T. Maugard, M. Remaud-Simeon, D. Petre, P. Monsan, J. Mol. Catal. - B Enzym. 1998, 5, 13-17.

[8] M. Ho, "Clariant: Sugar Surfactant Open Innovation Challenge," can be found under https://clariantsurfactantchallenge.innoget.com/, 2021.

[9] M. R. Petchey, G. Grogan, Adv. Synth. Catal. 2019, 361, 38953914.

[10] E. Romero, B. S. Jones, B. N. Hogg, A. Rué Casamajo, M. A Hayes, S. L. Flitsch, N. J. Turner, C. Schnepel, Angew. Chemie Int. Ed. 2021, anie.202014931.

[11] M. Winn, S. M. Richardson, D. J. Campopiano, J. Micklefield, Curr. Opin. Chem. Biol. 2020, 55, 77-85.

[12] H. K. Philpott, P. J. Thomas, D. Tew, D. E. Fuerst, S. L. Lovelock, Green Chem. 2018, 20, 3426-3431.

[13] P. M. Marchetti, S. M. Richardson, N. M. Kariem, D. J. Campopiano, Medchemcomm 2019, 10, 1192-1196.

[14] M. Z. Abidin, T. Saravanan, E. Strauss, G. J. Poelarends, Org Biomol. Chem. 2021, 19, 4515-4519.

[15] S. R. Derrington, N. J. Turner, S. P. France, J. Biotechnol. 2019, 304, 78-88.

[16] D. Gahloth, M. S. Dunstan, D. Quaglia, E. Klumbys, M. P. LockhartCairns, A. M. Hill, S. R. Derrington, N. S. Scrutton, N. J. Turner, D. Leys, Nat. Chem. Biol. 2017, 13, 975-981.

[17] A. J. L. Wood, N. J. Weise, J. D. Frampton, M. S. Dunstan, M. A. Hollas, S. R. Derrington, R. C. Lloyd, D. Quaglia, F. Parmeggiani, D. Leys, N. J. Turner, S. L. Flitsch, Angew. Chemie - Int. Ed. 2017, 56, 14498-14501.

[18] M. Lubberink, C. Schnepel, J. Citoler, S. R. Derrington, W. Finnigan, M. A. Hayes, N. J. Turner, S. L. Flitsch, ACS Catal. 2020, 10, 10005-10009.

[19] P. Pongpamorn, C. Kiattisewee, N. Kittipanukul, J. Jaroensuk, D. Trisrivirat, S. Maenpuen, P. Chaiyen, Angew. Chemie Int. Ed. 2021, 60, 5749-5753.

[20] W. Finnigan, A. Thomas, H. Cromar, B. Gough, R. Snajdrova, J. P. Adams, J. A. Littlechild, N. J. Harmer, ChemCatChem 2017, 9, 1005-1017.

[21] D. Schwendenwein, A. K. Ressmann, M. Doerr, M. Höhne, U. T. Bornscheuer, M. D. Mihovilovic, F. Rudroff, M. Winkler, Adv. Synth. Catal. 2019, 2544-2549.

[22] M. L. Contente, A. Pinto, F. Molinari, F. Paradisi, Adv. Synth. Catal. 2018, 360, 4814-4819.

[23] M. L. Contente, D. Roura Padrosa, F. Molinari, F. Paradisi, Nat. Catal. 2020, 3, 1020-1026.

[24] R. Cairns, A. Gomm, J. Ryan, T. Clarke, E. Kulcinskaja, K. Butler, E. O'Reilly, ACS Catal. 2019, 9, 1220-1223.

[25] M. Winn, M. Rowlinson, F. Wang, L. Bering, D. Francis, C. Levy, J. Micklefield, Nature 2021, 593, 391-398.

[26] M. Petchey, A. Cuetos, B. Rowlinson, S. Dannevald, A. Frese, P. W. Sutton, S. Lovelock, R. C. Lloyd, I. J. S. Fairlamb, G. Grogan, Angew. Chemie - Int. Ed. 2018, 57, 11584-11588.

[27] M. R. Petchey, B. Rowlinson, R. C. Lloyd, I. J. S. Fairlamb, G. Grogan, ACS Catal. 2020, 10, 4659-4663.
M. Lubberink, C. Schnepel, J. Citoler, S. R. Derrington, W. Finnigan, M. A. Hayes, N. J. Turner, S. L. Flitsch, ACS Catal. 2020, 10, 10005-10009.

[29] F. Subrizi, L. Benhamou, J. M. Ward, T. D. Sheppard, H. C. Hailes, Angew. Chemie Int. Ed. 2019, 58, 3854-3858.

[30] B. P. Nocek, A. N. Khusnutdinova, M. Ruszkowski, R. Flick, M. Burda, K. Batyrova, G. Brown, A. Mucha, A. Joachimiak, L. Berlicki, A. F. Yakunin, ACS Catal. 2018, 8, 10746-10760.

[31] A. Goswami, S. G. Van Lanen, Mol. Biosyst. 2015, 11, 338-353.

[32] L. L. Cameron, S. C. Wang, R. Kluger, J. Am. Chem. Soc. 2004, 126, 10721-10726.

[33] J. Wodzinska, R. Kluger, J. Org. Chem. 2008, 73, 4753-4754. 


\section{Entry for the Table of Contents}

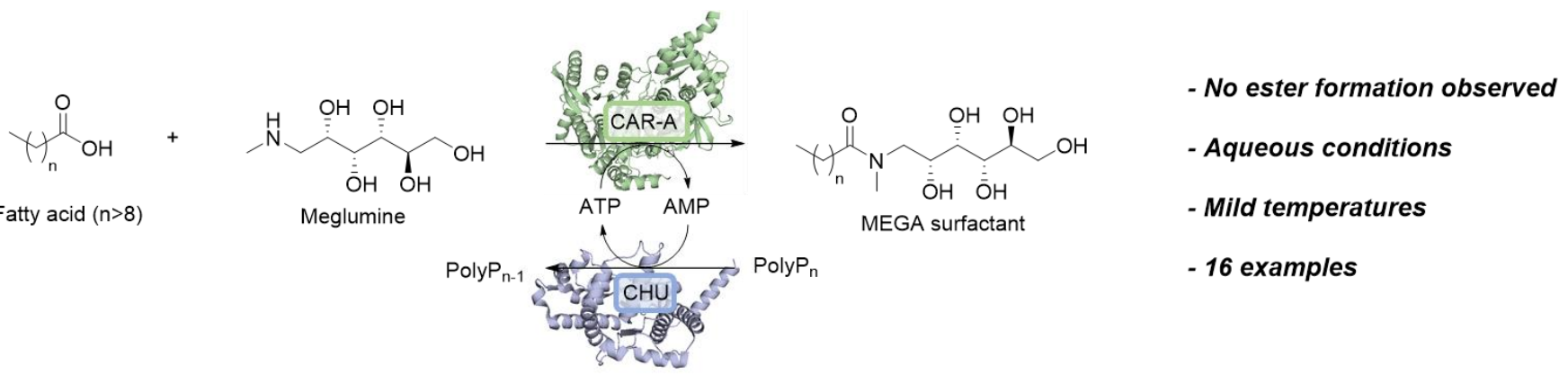

An enzymatic route to commercially important surfactants is presented here. A truncated construct of carboxylic acid reductase (CAR-A) catalyzes selective amide bond formation between fatty acids and amino alcohols with no esterification being observed. The wide substrate scope of this enzyme was exploited to synthesize 16 surfactants. Up-scaling and co-factor recycling show the feasibility of this method for synthetic applications.

Institute and/or researcher Twitter usernames: @makslub @Turner_Biocat @FlitschSabine @UoMMIB 